\title{
Expansão urbana e variações mesoclimáticas em João Pessoa, PB
}

\author{
Urban sprawl and mesoclimatic variations in João Pessoa - \\ $P B$
}

\section{Liése Carneiro Sobreira \\ Solange Maria Leder \\ Francisco de Assis Gonçalves da Silva \\ Paulo Roberto de Oliveira Rosa}

\section{Resumo}

A

cidade de João Pessoa, na Paraíba, vem sendo submetida, nos últimos anos, a um forte crescimento urbano. Nesse contexto, este trabalho verificou entre as décadas de 1980 e 2000 variações climáticas significativas que possam ser correlacionadas com o crescimento urbano. Para tanto, utilizaram-se imagens de satélite nos anos de 1977 e 2009 para o cálculo da área edificada, bem como foram utilizadas séries de dados das variáveis climáticas: precipitação pluviométrica e temperatura do ar, colhidas em duas estações instaladas na malha urbana, e uma terceira, tomada como estação de referência, fora da malha urbana. Para a caracterização do crescimento da cidade, utilizaram-se dados quantitativos da população residente constantes dos censos demográficos de 1872 a 2009. Para a verificação do ritmo do comportamento da

Liése Carneiro Sobreira Departamento de Arquitetura, Centro de Tecnologia Universidade Federal da Paraíba Campus I - Cidade Universitária

Joao Pessoa - PB - Brasil CEP 58059-900 Tel.: (083) 3216-7200 E-mail: lica1704@yahoo.com.br

Solange Maria Leder Departamento de Arquitetura, Centro de Tecnologia Universidade Federal da Paraíba
Tel.: (83) 3216-7378 Universidade Federal da Paraíba
Tel.: (83) 3216-7378 E-mail: solangeled:

Francisco de Assis Gonçalves da Silva Departamento de Arquitetura, Centro de Tecnologia

Universidade Federal da Paraíba E-mail: ffagos@yahoo.com.br

Paulo Roberto de Oliveira Rosa Departamento de Arquitetura, Centro de Tecnologia

Universidade Federal da Paraíba Tel.: (83) 216-7432 E-mail: paulorosa_ufpb@hotmail.com

Recebido em 12/08/10 Aceito em 25/03/11 série temporal de temperatura e precipitação foram gerados gráficos da temperatura média e do acumulado mensal dos meses correspondentes aos trimestres mais quentes e menos quentes do período de 1984 a 2008. Dos resultados obtidos do tratamento e análise dos dados pode-se verificar que a temperatura do ar da cidade aumentou nos últimos 26 anos, havendo-se detectado que as temperaturas do ar sofreram elevações mais expressivas nos meses do trimestre mais quente, fato que pode ser correlacionado com a expansão da malha urbana.

Palavras-chave: Clima urbano. Adensamento urbano. Variação climática.

\section{Abstract}

The city of João Pessoa, in the state of Paraiba, has experienced a strong check whether there were significant climate variations that could be linked with the urban growth of the city between the 1980's and 2000's. In order to do that, satellite images from 1977 and 2009 were used to calculate the urban sprawl area. In addition, a series of measurements of climate variables was used: rainfall and air temperature, taken from two weather stations located in the urban area, and another station outside the city. Quantitative data about the population were used to check urban growth, taken from the demographic censuses from 1872 to 2009. To verify the behavioral pace of the rainfall and temperature, charts were drawn containing the average temperatures and the monthly sum of the months in the warmest and least warm quarters from 1984 to 2008. The results of the data processing and analysis indicate that the air temperature in the city has increased over the past 26 years. Air temperature was also found to have increased more significantly in the months in the warmest quarter, which can be correlated with the expansion of urban sprawl.

Keywords: Urban climate. Urban sprawl. Climate variations. horizontal and vertical urban growth in recent years. The aim of this study was to 


\section{Introdução}

O clima da Terra está em constante flutuação, como aponta Marsh e Dozier (1981). Atualmente a Terra está mais aquecida do que há milhões de anos, no entanto mais fria do que há bilhões de anos. Com isso, é possível perceber que a Terra tem um dinamismo natural de mudanças climáticas. Contudo, vem sendo observado que as ações humanas estão acelerando esse processo natural, em que podem ser observadas mudanças desde a escala global até variações no clima local, sobretudo nos grandes e médios aglomerados urbanos.

As transformações da paisagem natural, que ocorrem com a substituição desta pelos equipamentos urbanos em decorrência da ampliação e do crescimento da malha urbana, provocam notáveis mudanças no clima local, fazendo com que o clima da cidade revele-se diferente do clima do campo circundante.

Com isso, visto que metade da população mundial reside em áreas urbanas, ${ }^{1}$ o estudo do clima desse espaço torna-se de grande relevância. A Teoria do Sistema Clima Urbano (SCU), elaborada por Monteiro (1975), estabelece um modelo teórico explicativo do fenômeno clima urbano, sendo considerados três canais de percepção do ser humano: conforto térmico; qualidade do ar; e impacto meteórico. Para Monteiro (2003), o clima urbano observado numa perspectiva geográfica deve ser entendido como o clima dentro da cidade, diferentemente da abordagem meteorológica, que entende o clima urbano como o clima acima da cidade.

Estudos aplicados a algumas cidades brasileiras, tendo como referência a teoria do SCU (SAMPAIO, 1981; ASSIS, 1990; DUARTE, 2000; BRANDÃO, 1996), demonstraram a complexidade e a dinâmica das interações entre clima e forma urbana. As pesquisas de Brandão (1996) e Duarte (2000) conduzem ao entendimento de quanto os índices de correlação entre a temperatura do ar e as variáveis independentes da forma urbana consideradas podem variar ao longo do tempo, dadas as flutuações atmosféricas durante o período de observação de séries de dados climáticos, demonstrando que os usos de métodos de correlação carecem ser acrescidos de critérios de significância das correlações para que a análise se torne mais precisa.

Carvalho (2006) traz à tona elementos importantes para a discussão e revisão de conceitos até então adotados em diversos trabalhos sobre climatologia

\footnotetext{
${ }^{1}$ Organização das Nações Unidades (ONU). Disponível em:
} <http://esa.un.org/unup/>. urbana, em especial sobre as interações dinâmicas entre elementos do clima e da morfologia urbana em localidades situadas em clima quente-úmido em baixa latitude. Em termos específicos, os resultados demostraram em quanto o processo de urbanização tem modificado o clima da cidade de João Pessoa, formando ilhas de calor significativas e evidenciando a fragilidade dos parâmetros de planejamento estabelecidos na legislação urbana vigente.

Silva (1999), Ferraz (2003), Peregrino (2005), Queiroga (2005) e Guerra (2005) demonstraram que a forma da cidade, através das dimensões e orientação das edificações, dos afastamentos entre elas e da orientação da malha urbana, modifica o escoamento de vento, repercutindo significativamente nas condições de temperatura e de qualidade do ar no interior da cidade e dos edifícios. Os resultados desses trabalhos remetem à necessidade de aperfeiçoamento dos métodos de observação e de análise do clima urbano, sobretudo da análise do comportamento de outras variáveis climáticas além do da temperatura do ar, como a umidade relativa do ar, a direção e a velocidade do vento, a nebulosidade, a radiação solar incidente e a temperatura de superfícies verticais e horizontais.

Os estudos realizados até este momento revelaram que o processo de urbanização altera os escoamentos do vento, elevando a camada limite atmosférica e reduzindo a velocidade próxima da superfície (CHANDLER, 1976; SILVA, 1999). Tal efeito é potencializado à medida que se aumenta a rugosidade da superfície do solo de determinado lugar geográfico. Entretanto, estudos realizados em algumas cidades litorâneas, como Salvador (SAMPAIO, 1981), Maceió (BARBIRATO, 1999), João Pessoa (SILVA, 1999; FERRAZ, 2003; PEREGRINO, 2005) e Rio de Janeiro (CORBELLA; YANNAS, 2003; SOUZA E SILVA, 2003), indicam que há aí uma relação mais complexa, em que a forma urbana (orientação, dimensões e organização das edificações no espaço) e a orografia condicionam a ventilação, que, por sua vez, influencia de maneira diferenciada o comportamento térmico de determinada porção urbana.

Nesse contexto, as relações entre a expansão urbana e as variações climáticas decorrentes é o foco principal deste trabalho. Esta investigação de observação direta e sistematizada, utilizando dados de três estações climatológicas e de geotecnologias, como imagens de satélite, permitiu processar superposições e daí retirar informações sobre a relação entre o crescimento urbano e as 
variações climatológicas nos elementos de clima temperatura e precipitação.

João Pessoa, capital do Estado da Paraíba, como todas demais capitais do país, teve crescimento acentuado por constituir-se em um polo atrativo para migrantes em busca de melhor qualidade de vida e de oportunidade de emprego. A política recepcionista é uma referência constitucional no que diz respeito ao direito de ir e vir do cidadão brasileiro em todo o território nacional, contudo o crescimento desordenado gera, entre outros, conflitos ambientais.

A população da cidade cresceu e, consequentemente, a área urbana da cidade de João Pessoa expandiu-se tanto horizontal como verticalmente. $\mathrm{O}$ crescimento horizontal significou a impermeabilização do solo, o que acaba por impedir a troca de matéria e energia entre o solo e subsolo e a atmosfera. Com o aumento da impermeabilização, a carga de energia que atinge o solo é redirecionada pela camada impermeabilizante e refletida de volta à atmosfera, formando assim um ciclo térmico em toda a sua extensão.

Isso posto, o objetivo geral da pesquisa é identificar as possíveis variações climáticas, sobre os registros da temperatura do ar e da precipitação, na cidade de João Pessoa decorrentes da expansão urbana entre as décadas de 1980 a 2000.

\section{Metodologia}

Para a medição da evolução da área da malha urbana da cidade foram utilizadas as imagens do satélite LANDSAT 2 do ano de 1977 e do satélite CBERS 2B de 2009; essas imagens estão disponíveis para download na página web do Instituto Nacional de Pesquisas Espaciais (INPE). Posteriormente, as imagens de satélites foram processadas em um software de sistema de informação geográfica (SIG) e tiveram sua área edificada calculada com base na malha urbana identificada nas imagens, através do programa SPRING, versão 5.1 para Windows. ${ }^{2}$ Somente as imagens dos anos de 1977 e 2009 foram utilizadas, visto que as outras imagens de satélite disponíveis encontravam-se com a área urbana de João Pessoa coberta ou parcialmente coberta por nuvens, o que não possibilitaria a medição da malha urbana. Para complementar os dados obtidos com as imagens de satélites e preencher a lacuna temporal resultante, utilizou-se o trabalho de Rodriguez (1985), que contém estudo sobre a evolução da área urbana na

\footnotetext{
${ }^{2}$ Disponível para download em:

<http://www.dpi.inpe.br/spring/>.
}

cidade de João Pessoa para os anos de 1920, 1950, 1970 e 1978.

O crescimento demográfico foi outra variável associada com o crescimento urbano e também analisada neste trabalho. Foram utilizados dados dos censos demográficos de 1872 a 2009 , disponíveis no portal Cidades do sítio web do Instituto Brasileiro de Geografia e Estatística (IBGE). De posse dos dados, gerou-se em planilha eletrônica um gráfico demonstrando a evolução da população residente na cidade de João Pessoa dos anos de 1872, 1900, 1920, 1940, 1950, 1960, 1970, 1980, 1991, 1996, 2000, 2007 e 2009 correspondentes aos anos em que se realizou contagem da população no Brasil.

Para a verificação da relação entre expansão urbana e as variações climáticas na cidade de João Pessoa, foram escolhidas as variáveis temperatura do ar e precipitação pluviométrica, porque essas são variáveis que influenciam diretamente as atividades humanas. As séries de dados de temperatura do ar e de precipitação foram colhidas em três estações meteorológicas, sendo duas localizadas na malha urbana da cidade, a estação do Laboratório de Energia Solar (LES) da UFPB e a estação do Instituto Nacional de Meteorologia (INMET), e uma terceira tomada como estação de referência por estar situada fora da malha urbana, a estação do Aeroporto Castro Pinto (Figura 1).

A estação do LES, localizada na Universidade Federal da Paraíba - Campus I (latitude $7^{\circ} 08^{\prime}$, longitude $34^{\circ} 51^{\prime}$ e altitude $44,0 \mathrm{~m}$ ) realiza observações acerca do clima em João Pessoa desde 1975. Os dados são atualizados diariamente nos horários das 09h00, 15 h00 e 21h00, e são obtidos por meio de instrumentos analógicos.

A estação do INMET, localizada às margens da BR-230 (latitude $7^{\circ} 05^{\prime}$, longitude $34^{\circ} 50^{\prime}$ e altitude 5,0 m), no Ministério da Agricultura, coleta séries de dados climáticos desde 1962, registradas também de forma analógica três vezes ao dia, 09h00, $15 \mathrm{~h} 00$ e 21h00. Os dados do INMET foram solicitados em Brasília, onde há o arquivamento de todos os dados nacionais.

Por fim, a estação do Aeroporto Castro Pinto, em funcionamento desde 1973, localizada entre os municípios de Bayeux, Santa Rita e João Pessoa (latitude $7^{\circ} 08^{\prime}$, longitude $34^{\circ} 56^{\prime}$ e altitude 62,00 $\mathrm{m})$, à semelhança das outras utilizadas nesta pesquisa, registra dados três vezes ao dia, nos horários das 09h00, $15 \mathrm{~h} 00$ e $21 \mathrm{~h} 00$. Esses dados serviram para compor a análise para o município de João Pessoa, pelo fato de essa estação encontrar-se em ambiente externo ao da malha urbana e assim poder ser tomada como estação de referência. 


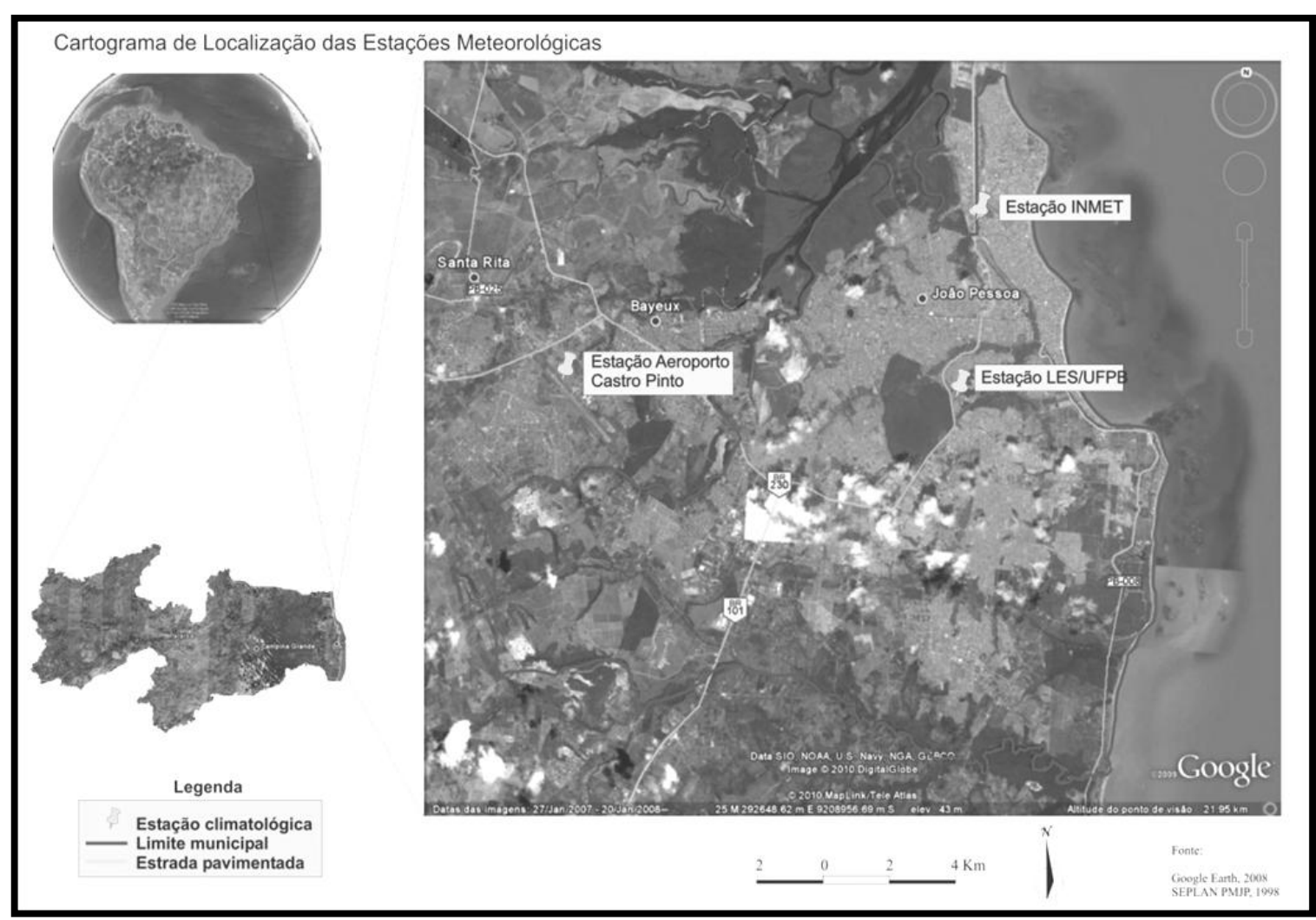

Figura 1 - Cartograma da localização da cidade de João Pessoa e das estações meteorológicas

Como foram encontradas falhas e lacunas nos bancos de dados das três estações meteorológicas utilizadas, optou-se por transformar os dados de temperatura em média mensal, e os de precipitação, em acumulado mensal, a fim de suprimir as limitações encontradas.

Em decorrência do volume de dados a serem analisados, optou-se pela análise dos meses do ano quando ocorrem os extremos. Assim, foram escolhidos os dados dos meses do trimestre mais quente, que se referem a janeiro, fevereiro e março, e os dados dos meses do trimestre menos quentes, que são os meses de junho, julho e agosto, das estações consideradas.

Para a verificação do ritmo do comportamento da série temporal de temperatura e precipitação foram gerados gráficos da temperatura média e do acumulado mensal dos meses dos trimestres mais quentes e menos quentes do período de 1984 a 2008. Com isso, foi possível uma descrição detalhada do comportamento da série desses períodos. Para a visualização da tendência dessas variáveis, foram elaborados, com o auxílio de planilha eletrônica, gráficos que representassem a tendência linear e a linha da média móvel. Esta última também foi escolhida pelo fato de suavizar flutuações de uma série de dados.

\section{Expansão urbana em João Pessoa}

Embora a cidade de João Pessoa seja uma das cidades mais antigas do país, ${ }^{3}$ que desde o início do século XX já evidenciava processo de ampliação de sua malha urbana, o crescimento urbano efetivo de João Pessoa, tanto pelo quesito relativo aos equipamentos urbanos quanto pelo contingente populacional, ocorreu de forma mais intensa a partir da década de 1970. Pode-se citar vários fatores responsáveis por esse processo. Sabe-se que o êxodo rural é um dos fenômenos de forte influência no aumento da população urbana. A expansão da Universidade Federal da Paraíba, a partir da década de 1970, também contribuiu para o incremento da população. Um elemento que leva à percepção do aumento populacional nesse período foi o surgimento de conjuntos habitacionais, construídos para suprir a demanda por moradia, como, por exemplo, o bairro de Mangabeira, localizado na zona sul da cidade.

É relevante mencionar que o aumento populacional da cidade de João Pessoa foi proporcionalmente maior do que o do Estado da Paraíba, e nas últimas três décadas a cidade quase triplicou o número de

${ }^{3}$ Denominada de Nossa Senhora das Neves, João Pessoa teve sua fundação em 1585 (REIS FILHO, 1968).

128 Sobreira, L. C.; Leder, S. M.; Silva, F. de A. G. da; Rosa, P. R. de O. 
seu contingente populacional, considerando que em 1970 a população residente era de 221.052 habitantes e, em 2009, segundo dados do IBGE, conta com 702.235 habitantes. No que se refere à expansão de sua malha urbana, verifica-se que a maior taxa de crescimento deu-se entre as décadas de 1950 e 1970. A área urbana de 1.145 ha foi ampliada para 3.788 ha, representando um aumento de $38 \%$ em apenas 20 anos. No entanto, chama a atenção que no intervalo de 7 anos, tempo referente aos anos de 1970 a 1977, a cidade cresceu 2.371 ha, correspondendo a um crescimento de $34 \%$, valor bastante alto, considerado o curto intervalo de tempo. Observase nesse período uma intensa expansão da área edificada na parte sudeste da cidade, com o surgimento dos bairros Jardim Cidade Universitária, Castelo Branco e Bancários, próximos ao campus da UFPB.

Nos últimos 30 anos, embora a cidade tenha sofrido um considerável aumento de seu contingente populacional, não houve expansão da área urbana, mas houve da área edificada, ou seja, ocorreu adensamento urbano. Pode-se observar durante os anos de 1977 a 2009 (Figura 2) que a malha urbana da cidade cresceu 1.959 ha, ou seja, a taxa de expansão urbana deste período foi de $28 \%$, um percentual relativamente pequeno considerando que de 1970 a 2009 a população residente na cidade teve um incremento de mais de 400 mil habitantes - ver gráfico da Figura 3 construído a partir dos dados de Rodriguez (1985) para 1920, 1950 e 1977; Satélites LANSAT 5 (1977); e CBERS 2B (2009).

Assim, observa-se que, do final da década de 1970 a 2009, a cidade de João Pessoa cresceu 28\%, o que pode ser entendido como uma expansão relativamente pequena, considerando que no mesmo período a população residente cresceu aproximadamente $140 \%$, indicando que a cidade sofreu um intenso processo de verticalização. A década de 1970 representou o início do processo de intensificação da urbanização em João Pessoa, sendo esse fenômeno atribuído à forte imigração que ocorreu na cidade a partir dessa época.
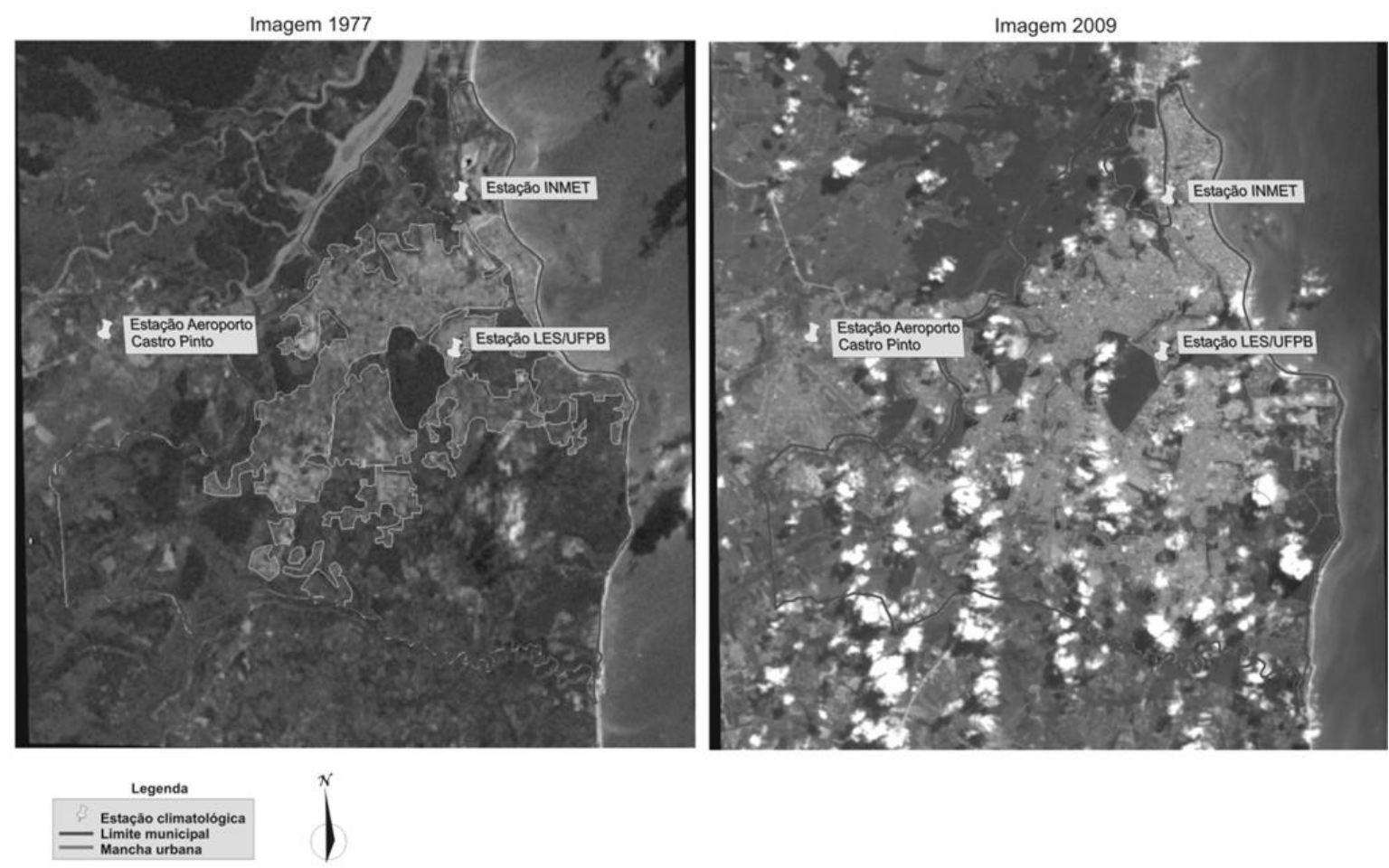

Figura 2 - Identificação da área edificada da cidade em dois momentos: 1977 e 2009 (imagens do satélite LANDSAT 2 de 1977 e do satélite CBERS 2B de 2009)

Fonte: INPE (2009). 


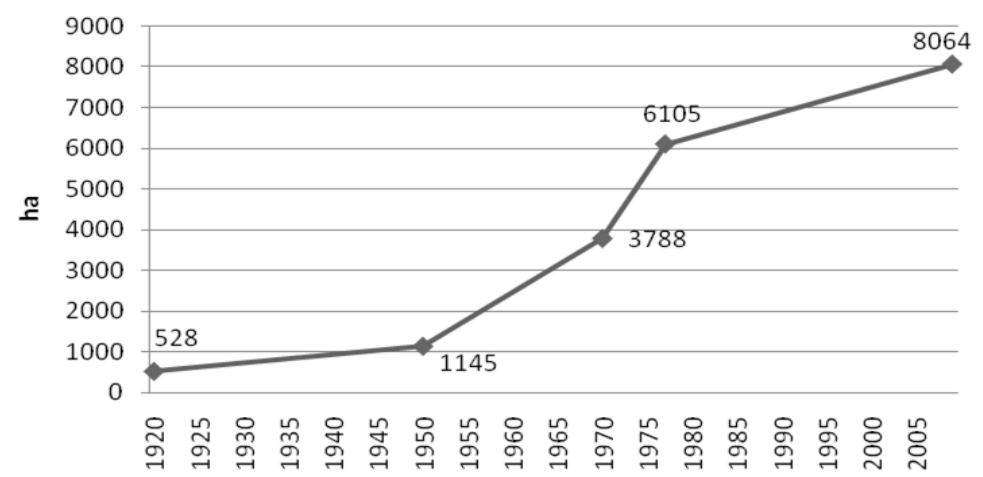

Figura 3 - Área da malha urbana de João Pessoa de 1920 a 2009

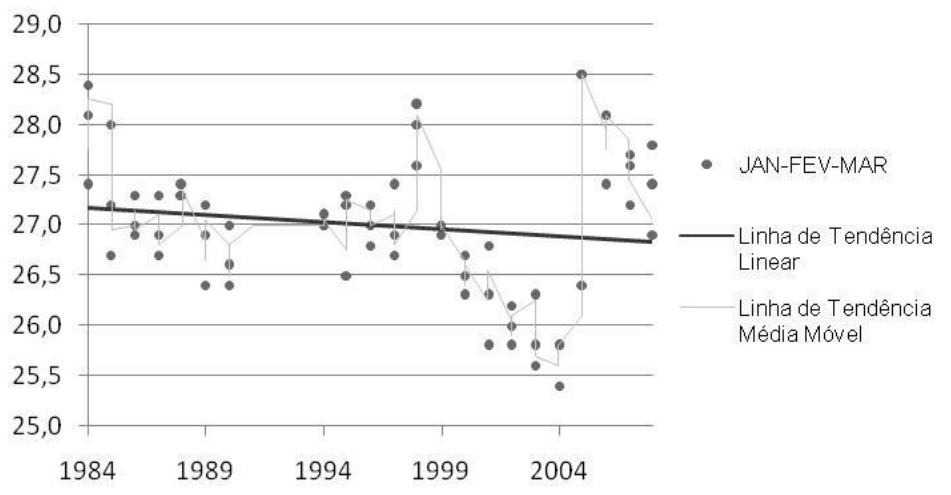

Figura 4 - Tendência de temperatura dos meses do trimestre mais quente da estação do Aeroporto Castro Pinto de 1984 a 2008

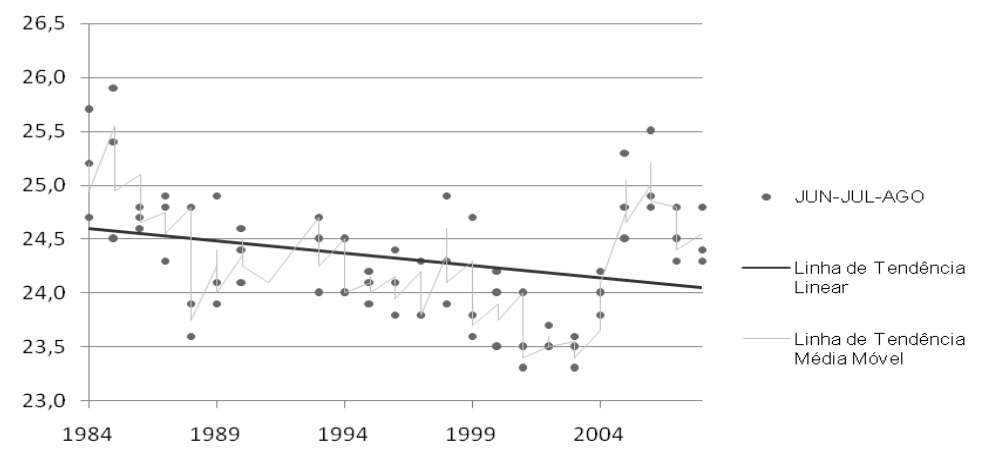

Figura 5 - Tendência de temperatura dos meses do trimestre menos quente da estação do Aeroporto Castro Pinto de 1984 a 2008

\section{Variações na temperatura do}

\section{ar}

Observando o desenvolvimento da curva de temperatura, com os dados da estação do Aeroporto Castro Pinto, no trimestre mais quente (Figura 4) verifica-se que há uma tendência de declínio. No entanto, observando a curva da média móvel, nota-se que o declínio da temperatura foi rompido por uma elevação de temperatura em 2005. Ainda que observada uma diminuição da temperatura nos últimos anos da série, esse decréscimo de temperatura não é tão acentuado como nas décadas de 1980 e 1990.

Pode-se perceber que, embora a série de dados do trimestre menos quente da estação do Aeroporto contenha intervalos de aumento e diminuição, a curva de tendência na Figura 5 indicou que houve declínio da temperatura. Contudo, ao examinar a linha da média móvel, nota-se que, mesmo havendo uma curva de declínio nos últimos anos da série, a partir de 2003 a temperatura está mais elevada do que nos anos anteriores. 
A curva de tendência da temperatura da estação do LES do trimestre mais quente indica que houve uma expressiva elevação da temperatura, uma elevação de $0,5^{\circ} \mathrm{C}$. Já a curva da média móvel demonstra que houve três períodos de aquecimento, sendo um no final da década de 1980, outro na última metade da década de 1990, e o terceiro nos últimos anos da série, à exceção de 2008. Percebe-se que, à exceção do pico de temperatura ocorrido em 1998 , próximo a $30^{\circ} \mathrm{C}$, o período de aquecimento dos últimos anos da série é mais elevado do que os dois outros períodos de elevação da temperatura ocorridos nas décadas de 1980 e 1990 (Figura 6).

Na Figura 7 pode-se observar a linha de tendência da temperatura do trimestre menos quente da estação do LES, demonstrando que não houve aquecimento nesse período. Da mesma forma, na curva da média móvel não se detectou tendência de elevação da temperatura. Verifica-se, no entanto, que as temperaturas mínimas, de modo geral, são superiores a $25,5^{\circ} \mathrm{C}$ a partir da segunda metade da década de 1990.

O gráfico da tendência do trimestre mais quente da estação do INMET aponta que houve um expressivo aumento da temperatura no período de 1984 a 2008, superior a 0,5 ${ }^{\circ} \mathrm{C}$. Esse comportamento de elevação torna-se nítido na linha da média móvel, o ano de 1998, e os quatro últimos anos da série contêm registros mais elevados de temperatura, com a média em torno de $29,5{ }^{\circ} \mathrm{C}$. Observa-se que, em média, as temperaturas mínimas dos últimos anos da série, de modo geral, são mais elevadas do que as temperaturas dos anos de 1980 e 1990 (Figura 8).

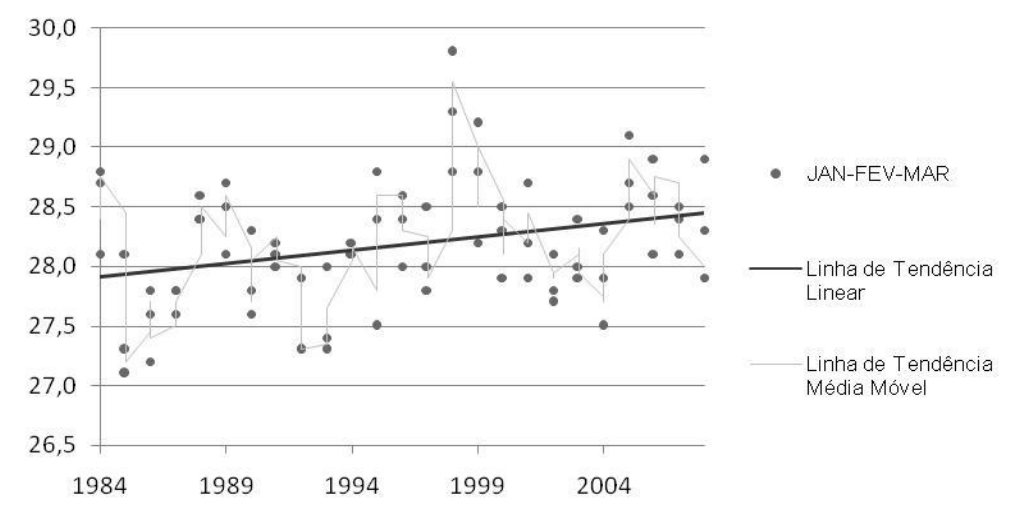

Figura 6 - Tendência de temperatura média dos meses do trimestre mais quente da estação do LES de 1984 a 2008

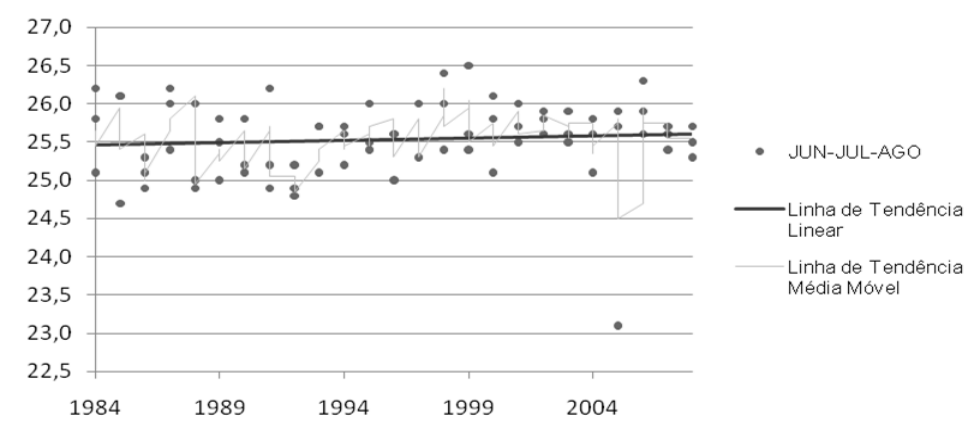

Figura 7 - Tendência de temperatura média dos meses do trimestre menos quente da estação do LES de 1984 a 2008 


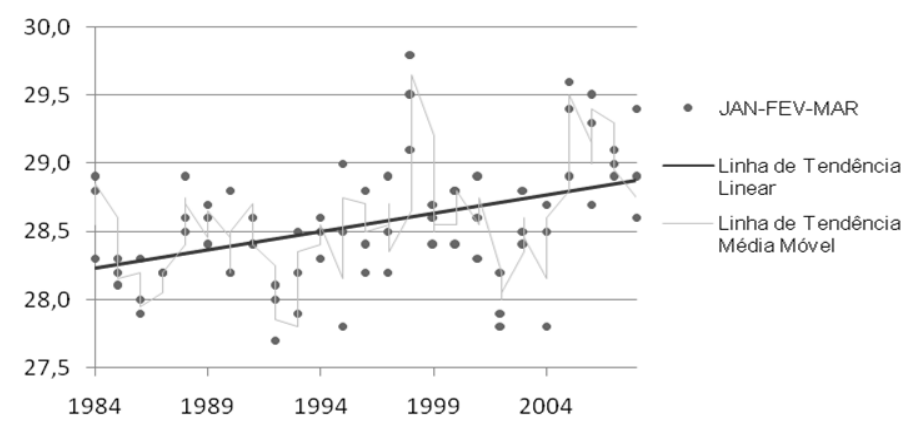

Figura 8 - Tendência de temperatura média do trimestre mais quente da estação do INMET de 1984 a 2008

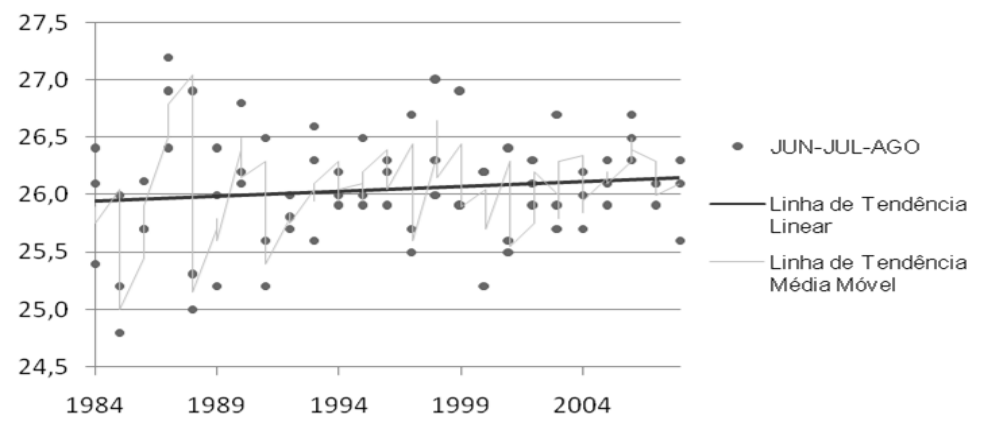

Figura 9 - Tendência de temperatura média do trimestre menos quente da estação do INMET de 1984 a 2008

Na Figura 9 pode-se observar que houve uma suave tendência de aquecimento na série de temperatura do trimestre menos quente do INMET no período de 1984 a 2008. Na curva da média móvel percebe-se também que não houve elevação da temperatura, mas fica evidente que a partir de 1994 ocorre um aumento das mínimas (ocorrências acima de $25,5^{\circ} \mathrm{C}$ ), com poucas exceções.

A partir da descrição do ritmo da temperatura do ar dos trimestres mais quentes (janeiro/fevereiro/março) e dos trimestres menos quentes (junho/julho/agosto) das estações meteorológicas do Aeroporto, do LES e do INMET, referente ao período de 1984 a 2008, fazse necessária a consideração de algumas observações pertinentes ao comportamento térmico da série.

As observações feitas na estação meteorológica de referência, a do Aeroporto, evidenciam comportamento semelhante nos trimestres mais quentes e nos menos quentes, em que foi verificado um declínio de temperatura até 2003, quando a partir de então se iniciou um período de aquecimento.

Nas estações situadas no perímetro urbano, LES e INMET, observaram-se comportamentos diferenciados nos trimestres mais e menos quentes. Verifica-se que houve uma considerável elevação da temperatura do ar no trimestre mais quente nas duas estações, acima de $0,5^{\circ} \mathrm{C}$, sendo que a do INMET apresentou elevação mais intensa. Já no trimestre menos quente verificou-se uma suave tendência de elevação da temperatura, sendo observado, no entanto, que as temperaturas mínimas registradas estão mais elevadas nos últimos anos da série.

\section{Variações na precipitação pluviométrica}

Embora haja oscilações na série de dados de precipitação do trimestre mais quente da estação do Aeroporto de 1984 a 2008, pois ora se encontra mais elevada, ora mais baixa, verifica-se que há uma tendência de aumento do acumulado mensal das precipitações, como demonstrado na Figura 10. $\mathrm{Na}$ curva da média móvel pode-se ver que a elevação da precipitação acumulada se deu principalmente no final dos anos 1990, entre os anos de 1995 e 1999, e no período de 2000 a 2004.

Observando a linha de tendência da precipitação do trimestre menos quente do Aeroporto (Figura 11), nota-se que há uma tendência de aumento do acumulado mensal. Observando a linha da média móvel, à exceção dos meses em que foram registrados acumulados mensais superiores à media que ocorreu em 1993 e do declínio que se seguiu posteriormente a esse ano, percebe-se que a 
partir de 2000 a precipitação mantém comportamento regular, não havendo curva de declínio e/ou de elevação acentuada.

A partir da Figura 12, gráfico da tendência da precipitação do trimestre mais quente medida na estação do LES, pode-se notar que não houve tendência de elevação nem de declínio da precipitação. Observando a linha da média móvel, percebe-se que o declínio mais longo e acentuado da precipitação ocorreu de 1985 a 1990, não se verificando períodos longos de aumento ou de diminuição do acumulado. As décadas de 1990 e 2000 caracterizaram-se por constantes oscilações do acumulado das precipitações mensais. Esses anos contêm intervalos nos quais ora a precipitação esteve mais elevada, ora mais baixa, não sendo verificada a predominância de nenhuma dessas variações.

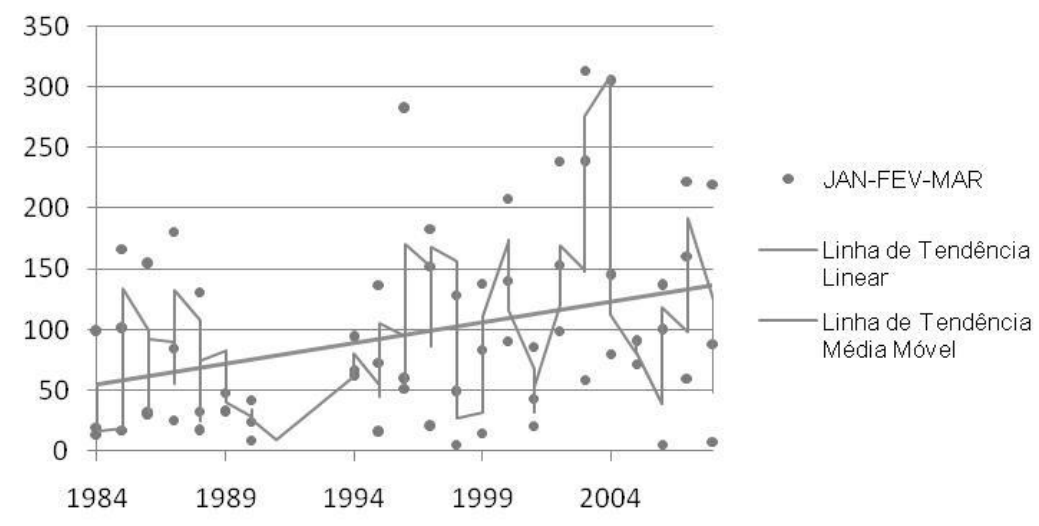

Figura 10 - Tendência de precipitação do trimestre mais quente da estação do Aeroporto de 1984 a 2008

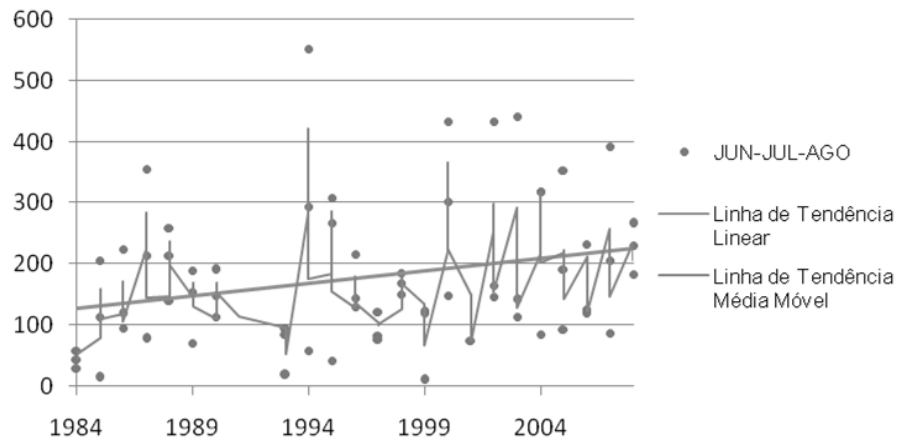

Figura 11 - Tendência de precipitação do trimestre menos quente da estação do Aeroporto de 1984 a 2008

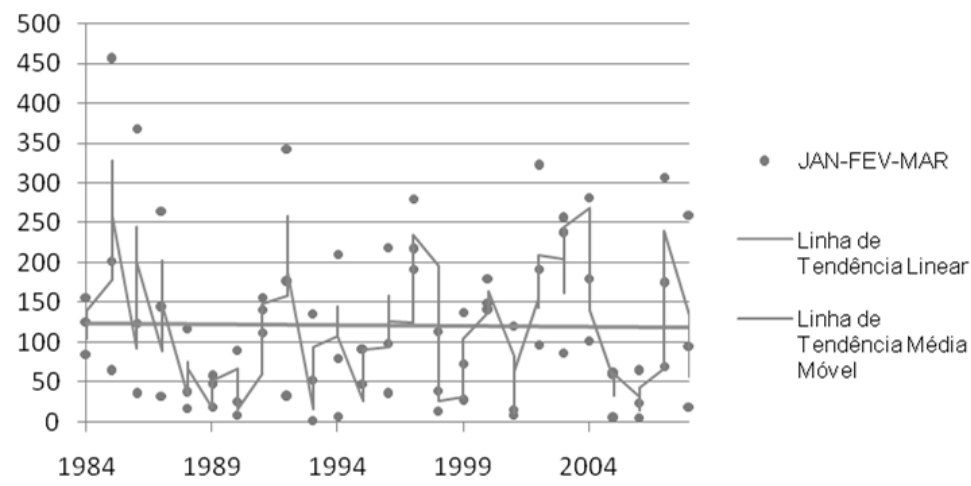

Figura 12 - Tendência de precipitação do trimestre mais quente da estação do LES de 1984 a 2008 


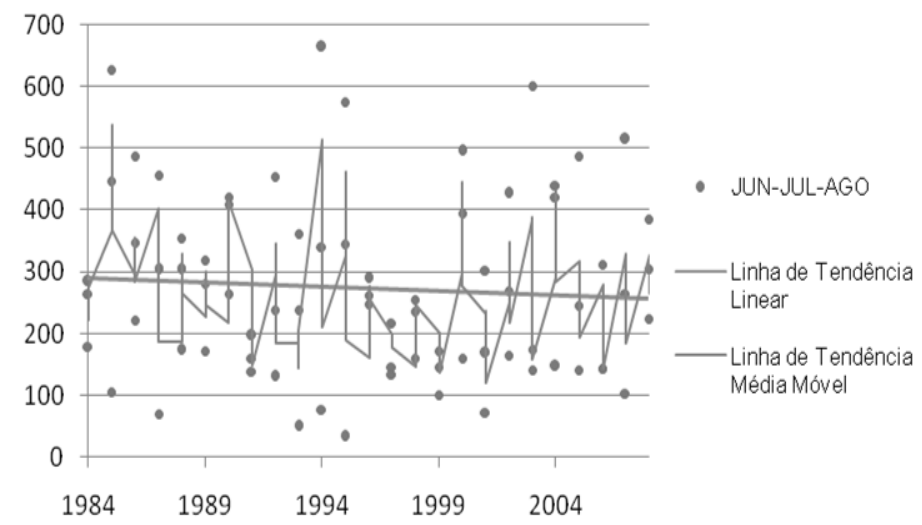

Figura13 - Tendência de precipitação do trimestre menos quente da estação do LES de 1984 a 2008

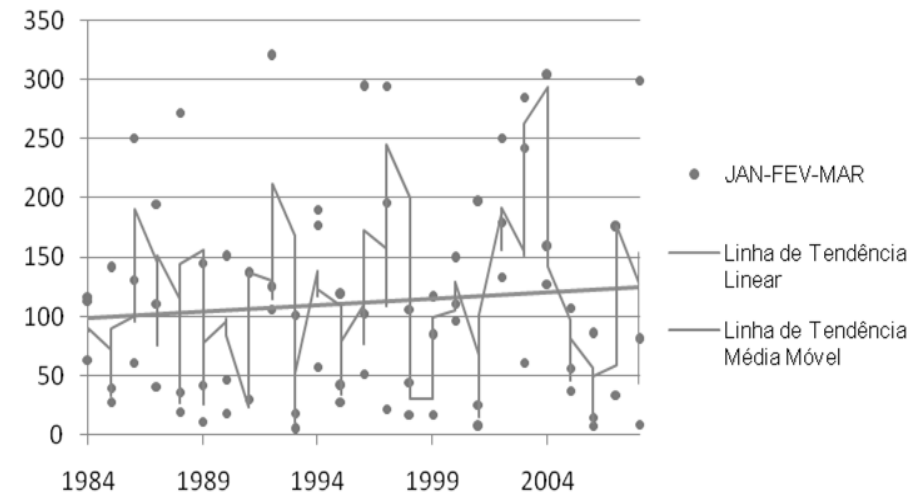

Figura 14 - Tendência de precipitação dos meses do trimestre mais quente da estação do INMET de 1984 a 2008

A curva de tendência da precipitação do trimestre menos quente da estação do LES, representada na Figura 13, demonstra que houve um suave declínio da precipitação no período de 1984 a 2008. Esse declínio pode ser observado na linha das médias móveis, em que se nota a existência de dois períodos longos de declínio de precipitação, sendo um de 1985 a 1993 e outro de 1995 a 1999. Contudo, pode-se perceber que a partir de 2000 não há longos períodos de declínio da precipitação, bem como as mínimas mensais acumuladas são, de modo geral, superiores a $100 \mathrm{~mm}$.

A partir do gráfico da tendência da precipitação do trimestre mais quente medida na estação do INMET no período de 1984 a 2008 (Figura 14), verifica-se que há aumento do acumulado mensal da precipitação nesse trimestre. Observando a curva da média móvel, à exceção dos períodos mais longos de declínio da precipitação, nota-se que há um aumento no acumulado mensal no início da década de 1990 até 2004. Nos últimos anos da série observa-se uma diminuição no acumulado mensal da precipitação.

O gráfico da tendência da precipitação do trimestre menos quente referente à estação do INMET, de
1984 a 2008, indica uma suave elevação do acumulado mensal da precipitação nesse trimestre ao longo dos anos (Figura 15). Corroborando o que foi descrito acima, observando a linha da média móvel, verifica-se um declínio da precipitação de 1984 até 1999, quando, a partir de então, se inicia um período de aumento do acumulado da precipitação.

A partir da descrição do ritmo da precipitação nos meses do trimestre mais quente (janeiro/fevereiro/março) e nos meses do trimestre menos quente (junho/julho/agosto) das estações meteorológicas do Aeroporto, LES e INMET no período de 1984 a 2008, constata-se que os dados dessas estações assumiram comportamentos diferentes, tanto no trimestre mais quente quanto no menos quente.

Na estação do Aeroporto, de referência, por estar localizada em uma área com baixa taxa de urbanização, ocorreu elevação do acumulado da precipitação nos dois trimestres, sendo esse aumento mais expressivo a partir do ano 2000.

Nas estações localizadas no núcleo urbano, LES e INMET, as observações tiveram comportamentos 
diferenciados entre si. $\mathrm{Na}$ estação do LES detectou-se uma suave tendência de declínio nos trimestres mais quentes e menos quentes, sendo este último o que apresentou uma diminuição mais expressiva do acumulado mensal da precipitação. Ressalta-se que o declínio do trimestre mais quente foi mais acentuado na década de 1980 e nos últimos anos da série, enquanto a precipitação do trimestre menos quente registrou diminuição do acumulado nas décadas de 1980 e 1990.

Inversamente ao comportamento da estação do LES, na estação do INMET as observações indicaram uma tendência de elevação do acumulado mensal da precipitação nos trimestres mais quentes e menos quentes, sendo que no trimestre mais quente registrou-se elevação do acumulado.

Outro fator que deve ser observado é o fato de que, de modo geral, os meses e os períodos de elevados acumulados de precipitação são precedidos por um período em que são registradas precipitações inferiores à média da série. Tal comportamento é verificado nos trimestres mais quentes e menos quentes das três estações meteorológicos consideradas.

\section{Média anual da temperatura do ar}

Como descrito anteriormente, as temperaturas medidas nas estações do Aeroporto, do LES e do INMET não tiveram o mesmo padrão de comportamento durante os anos 1984 a 2008. O mesmo é verificado no gráfico das temperaturas médias anuais de cada estação.

As temperaturas na estação do Aeroporto registraram declínio até o ano de 2004, iniciando a partir desse ano elevação, justamente quando se iniciaram as obras de ampliação de suas instalações. Entretanto, mesmo após a ampliação do complexo aeroportuário, a temperatura média medida nessa estação manteve-se mais baixa do que as nas duas estações localizadas no perímetro urbano de João Pessoa, como se pode ver na Figura 16.

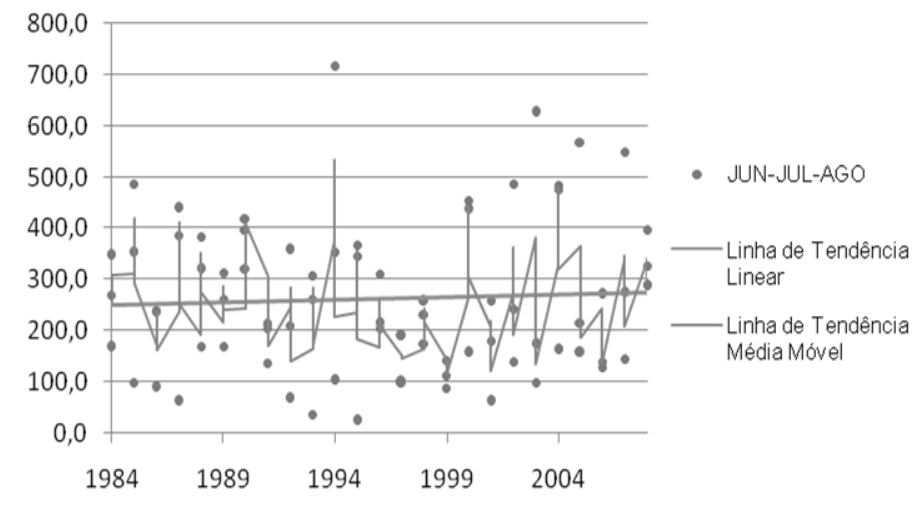

Figura 15 - Tendência de precipitação dos meses do trimestre menos quente da estação do INMET de 1984 a 2008

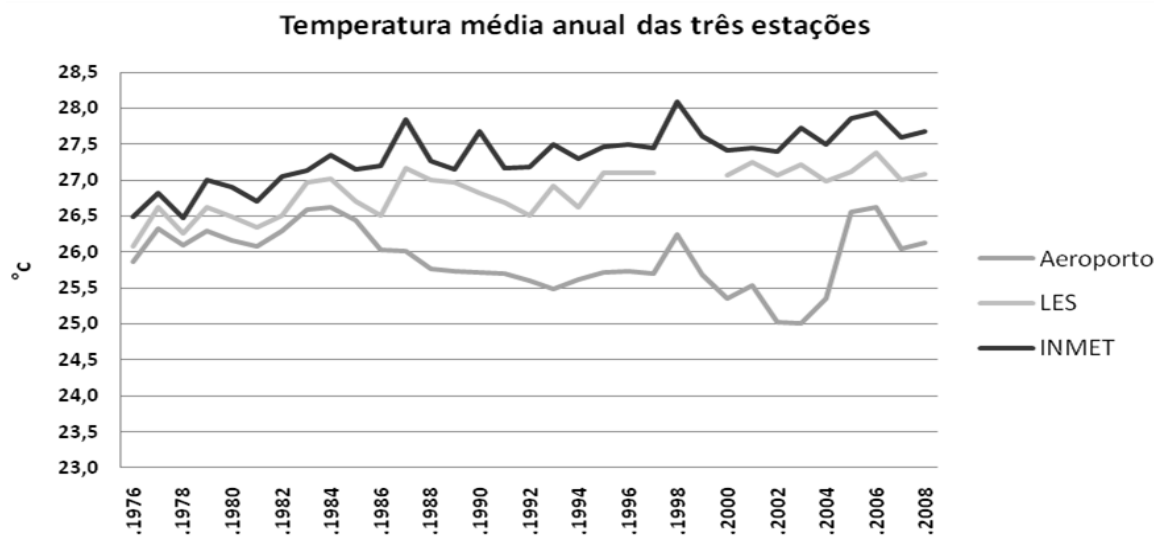

Figura 16 - Comparação da temperatura média anual nas três estações meteorológicas 
A temperatura média medida na estação do LES, embora seja mais elevada do que a da estação do Aeroporto é mais baixa do que a da estação do INMET. Tem-se em conta que a partir do final da década de 1970 a área onde se localiza a estação do INMET encontra-se com alto índice de adensamento, diferentemente da estação do LES, que se mantém em uma área com baixa densidade de urbanização. Outro fator que pode contribuir como regulador térmico das temperaturas registradas na estação do LES é o fato de essa estação estar próxima a extensos núcleos de vegetação, Mata Atlântica, situadas na área do Campus I da UFPB, e a reserva florestal da Mata do Buraquinho.

Embora seja verificada elevação da temperatura nos últimos anos das séries de dados medidas nas estações meteorológicas consideradas, verifica-se que a temperatura medida na estação do INMET é mais elevada do que nas outras duas estações. Observa-se que já no início da década de 1970 a estação do INMET encontrava-se em uma área urbanizada e que no decorrer das décadas seu entorno sofreu um grande aumento da área edificada, estando em 2009 em uma área densamente urbanizada e verticalizada. Diferentemente, na estação do Aeroporto, que se mantém em uma área com baixo nível de urbanização em seu entorno, ocorrem as temperaturas mais baixas ao longo dos anos.

Assim, com base na descrição do ritmo dos valores dos dados de temperatura do ar, na mensuração da área edificada da cidade de João Pessoa, bem como no levantamento de informações sobre a expansão urbana de alguns pontos da área estudada, pode-se inferir que existe uma relação entre o aumento da temperatura do ar, ocorrida nos três pontos de coleta da série de dados, e a expansão da malha urbana, ocorrida nas últimas décadas.

A estação do Aeroporto sofreu considerável elevação da temperatura a partir de 2004, momento do início da ampliação de suas instalações, com aumento da área edificada e da pista de pouso e decolagem. Entretanto, a observação das imagens disponíveis das citadas instalações, antes e depois de sua reforma, não evidencia grandes alterações em sua estrutura. Por isso, ainda que o aumento da temperatura coincida com a reforma do Aeroporto e este fato possa ser interpretado como um reflexo do aumento da área edificada, para a comprovação dessa relação é necessário o confronto com dados da expansão urbana ocorrida no entorno do aeroporto.

\section{Conclusões}

Sobre o comportamento das variáveis climatológicas, observadas em três estações na cidade de João Pessoa, pode-se afirmar que a temperatura do ar da cidade aumentou em decorrência de sua expansão urbana nos últimos 26 anos. Os resultados obtidos neste trabalho indicam que à medida que a área da malha urbana foi se expandindo houve um aumento da temperatura do ar no mesmo período. Também se verificou que os dados das estações meteorológicas tiveram comportamentos diferenciados de acordo com o nível de adensamento urbano de seu entorno, observando-se elevação mais significativa na estação do INMET, localizada em área de maior adensamento, assim como se observa maior tendência de elevação da temperatura nos trimestres mais quentes nas estações do LES e INMET.

Enquanto nas estações do LES e INMET a temperatura média anual tende a elevar-se, na do Aeroporto tende a baixar até o ano de 2004, quando as temperaturas se elevam, fato que pode ser interpretado como um reflexo da expansão da área edificada e da pista do Aeroporto Castro Pinto.

Com relação aos dados de precipitação, foi constatada tendência de aumento do acumulado mensal, tanto no trimestre mais quente quanto no menos quente, nas estações do Aeroporto Castro Pinto e do INMET. O aumento mais significativo da precipitação ocorreu na estação do Aeroporto, destacando-se a partir de 2004, quando ocorreu a expansão do Aeroporto, onde também se observou elevação da temperatura do ar. Nas estações situadas no núcleo urbano observaram-se diferenças entre si: a do LES tendeu a leve declínio, enquanto na do INMET ocorreu suave curva ascendente, sendo esta mais expressiva no trimestre mais quente.

\section{Referências bibliográficas}

ASSIS, Eleonora Sad de. Bases Teóricas para a Aplicação da Climatologia ao Planejamento Urbano. In: ENCONTRO NACIONAL DE CONFORTO NO AMBIENTE CONSTRUÍDO, 1., 1990, Gramado. Anais... Gramado: ANTAC, 1990.

BARBIRATO, G. M. O Uso da Modelagem Climática no Planejamento dos Espaços Urbanos. In: ENCONTRO LATINO-AMERICANO DE CONFORTO NO AMBIENTE CONSTRUÍDO, 5., 1999, Fortaleza. Anais... Fortaleza: ANTAC, 1999. 
BRANDÃO, Ana Maria P. M. O Clima Urbano da Cidade do Rio de Janeiro. 1996. São Paulo. Tese (Doutorado em Geografia) - Faculdade de Filosofia, Letras e Ciências Humanas, Universidade de São Paulo, São Paulo, 1996.

CARVALHO, Homero Jorge Matos de. Metodologia para a Análise das Interações entre a Forma Urbana e o Clima: aplicação a uma cidade brasileira de clima litorâneo com baixa latitude. 2006. Rio de Janeiro. Tese (Doutorado em Urbanismo) - Programa de Pós-Graduação em Arquitetura, Faculdade de Arquitetura e Urbanismo, Universidade Federal do Rio de Janeiro, Rio de Janeiro, 2006.

CHANDLER, T. J. Urban Climatology and Its Relevance to Urban Design. World Meteorological Organization, Geneva, v. 438, 1976.

CORBELLA, Oscar D.; YANNAS, Simos. Em Busca de uma Arquitetura Sustentável para os Trópicos. Rio de Janeiro: Revan, 2003.

DUARTE, D. Helena Silva. Padrões de Ocupação do Solo e Microclimas Urbanos na Região de Clima Tropical Continental. 2000. São Paulo. Tese (Doutorado em Arquitetura) Faculdade de Arquitetura e Urbanismo, Universidade de São Paulo, São Paulo, 2000.

FERRAZ, Aline Paiva Montenegro. Estudo da Repercussão das Variáveis Climáticas Decorrentes da Ocupação do Solo em Intermares. 2003. João Pessoa. Dissertação (Mestrado em Desenvolvimento e Meio Ambiente) - Programa de Pós-Graduação em

Desenvolvimento e Meio Ambiente, Universidade Federal da Paraíba, João Pessoa, 2003.

GUERRA, Viviane Maria de Melo. Verificação da Influência do Padrão de Ocupação do Solo Urbano no Topo de Parte da Falésia do Cabo Branco, em João Pessoa, PB, na Variável Climática Vento. 2005. João Pessoa. Dissertação (Mestrado em Engenharia Urbana) - Programa de Pós-Graduação em Engenharia Urbana e Ambiental, Universidade Federal da Paraíba, João Pessoa, 2005.

INSTITUTO NACIONAL DE PESQUISA

ESPACIAL. Catálogo de Imagens. 2009.

Disponível em: <http://www.dgi.inpe.br/CDSR/>. Acesso em: 15 set. 2009.

MARSH, M. W.; DOZIER, J. Landscape, an Introduction to Physical Geography. AddisonReading, MA: Wesley, 1981.
MONTEIRO, C. A. de F. Teoria e Clima Urbano. 1975. São Paulo. Tese (Livre-Docência em Geografia) - Faculdade de Filosofia, Letras e Ciências Humanas, Universidade de São Paulo, São Paulo, 1975.

MONTEIRO, C. A. F. Teoria e Clima Urbano. In: MONTEIRO, C. A. F.; MENDONÇA, F. (Org.). Clima Urbano. São Paulo: Contexto, 2003.

PEREGRINO, P. Inter-Relações Existentes entre os Escoamentos de Ventos e os Padrões de Ocupação do Solo nos Bairros do Cabo Branco e Tambaú, João Pessoa, PB. 2005. João Pessoa. 2005. Dissertação (Mestrado em Engenharia Urbana) - Programa de Pós-Graduação em Engenharia Urbana, Universidade Federal da Paraíba, João Pessoa, 2005.

QUEIROGA, Silvana C. C. de. Verificação da Eficiência do Dimensionamento de Aberturas para a Ventilação Natural nos Bairros do Cabo Branco e Tambaú, João Pessoa, PB. 2005. João Pessoa. Dissertação (Mestrado em Engenharia Urbana) - Programa de Pós-Graduação em Engenharia Urbana, Universidade Federal da Paraíba, João Pessoa, 2005.

REIS FILHO, Nestor Goulart. Contribuições ao Estudo da Evolução Urbana do Brasil (15001720). São Paulo: Pioneira, 1968.

RODRIGUEZ, J. L. A Evolução Urbana de João Pessoa. O Norte, João Pessoa, 5 de agosto de 1985.

SAMPAIO, A. H. L. Correlações Entre Uso do Solo Ilhas de Calor no Ambiente Urbano: o caso de Salvador. 1981. São Paulo. Dissertação (Mestrado em Geografia) - Faculdade de Filosofia, Letras e Ciências Humanas, Universidade de São Paulo, São Paulo, 1981.

SILVA, Francisco A. G. da. O Vento Como Ferramenta no Desenho do Ambiente Construído: uma aplicação ao Nordeste do Brasil. 1999. São Paulo. Tese ( Doutorado em Arquitetura) - Programa de Pós-Graduação em Arquitetura e Urbanismo, Universidade de São Paulo, São Paulo, 1999.

SOUZA E SILVA, C. A. de. Critérios para Aquisição e Análise de Dados Bioclimáticos Urbanos em Espaços Abertos Visando o Conforto Ambiental. 2003. Rio de Janeiro. Dissertação (Mestrado em Urbanismo) - Programa de Pós-Graduação em Urbanismo, Faculdade de Arquitetura e Urbanismo, Universidade Federal do Rio de Janeiro, Rio de Janeiro, 2003. 


\section{Agradecimentos}

À Capes, pelo auxílio financeiro, através de bolsa de estudo.

Revista Ambiente Construído Associação Nacional de Tecnologia do Ambiente Construído Av. Osvaldo Aranha, $99-3^{\circ}$ andar, Centro Porto Alegre - RS - Brasil CEP $90035-190$

Telefone: +55 (51) 3308-4084

Fax: +55 (51) 3308-4054 www.seer.ufrgs.br/ambienteconstruido

E-mail: ambienteconstruido@ufrgs.br 